\title{
LA INTERRUPCIÓN LEGAL DEL EMBARAZO Y EL ACTIVISMO DEL SIGLO XXI EN CHIAPAS
}

\section{The Legal Interruption of Pregnancy and Activism of the 2lth Century in Chiapas}

\author{
Alma Alejandra Soberano Serrano* \\ DOI: http://dx.doi.org/10.29043/liminar.v19i2.851
}

Resumen: La criminalización de la interrupción legal del embarazo ha sido en México un obstáculo constante al respeto de los derechos humanos de las mujeres en las legislaciones locales. Esta investigación aborda la visión y el trabajo realizado por tres organizaciones de mujeres de la sociedad civil que gestionan acciones en pro de esta interrupción legal en el estado de Chiapas. Se utilizó una metodología cualitativa a través de entrevistas en profundidad, considerando cuatro dimensiones de análisis. Entre los resultados más sobresalientes resalta la importancia del activismo en línea y la persistente necesidad de gestionar ante el poder legislativo reformas legales inminentes.

Palabras clave: interrupción legal del embarazo, derechos sexuales y reproductivos, activismo, feminismo, género.

Abstract: Criminalization of the legal termination of pregnancy in Mexico has continuously impeded respect for women's human rights in local legislation. This study discusses the vision and work carried out by three women's civil society organizations that undertake actions to promote legal termination of pregnancies in the state of Chiapas. A qualitative methodology was used involving in-depth interviews and four dimensions of analysis. The more notable results highlight the importance of carrying out online activism and direct advocacy around upcoming legal reforms before the legislature.

Key words: legal termination of pregnancy, sexual and reproductive rights, activism, feminism, gender.

\footnotetext{
* Alma Alejandra Soberano Serrano. Doctora en Estudios Regionales por la Universidad Autónoma de Chiapas, México. Profesora investigadora en la Facultad de Ciencias Administrativas y Sociales de la Universidad Autónoma de Baja California, campus Ensenada. Temas de especialización: derechos humanos, capital social y migración, legislación mexicana. Correo electrónico: alma.soberano@uabc.edu.mx. ORCID: https://orcid.org/0000-0003-0823-463X
}

Enviado a dictamen: 10 de agosto de 2020

Aceptación: 22 de febrero de 2021 


\section{Los derechos de salud sexual y reproductiva}

Cuando eres activista debes de ponerte bien la playera, porque empiezo a entender que el beneficio debe ser colectivo, es un trabajo (entrevista a Pato S., 28 de junio de 2019).

\section{L} os derechos relacionados con la salud sexual y reproductiva son parte de los derechos humanos; por ende, son universales e inherentes a los seres humanos, y su reconocimiento y respeto se vinculan a la dignidad humana, a la igualdad y a la libertad (ONU, s/f).

Estos derechos se conciben inicialmente como prerrogativas otorgadas hacia los padres en el sentido de decidir el número y la frecuencia para tener hijos; sin embargo, su reconocimiento y vinculación al actuar femenino es resultado de la Convención para la Eliminación de Todas las Formas de Violencia contra la Mujer (1979) y de la Declaración de Beijing ${ }^{1}$ (1995), lo que ha significado más de dos décadas de trabajo internacional para visualizar, reconocer y exigir a los gobiernos nacionales los derechos de las mujeres.

En la Conferencia de Beijing se define la salud reproductiva como: "la capacidad de disfrutar de una vida sexual satisfactoria y sin riesgos y de procrear, y la libertad para decidir hacerlo o no hacerlo, cuándo y con qué frecuencia" (ONU Mujeres, 2014:64). También se prevé la obligatoriedad de los Estados para proteger tales derechos desde sus textos constitucionales y en la consecuente aplicación de las normas relacionadas con su disfrute, lo que no ha sucedido en México.

Como consecuencia de esta omisión, este país ostenta índices alarmantes de embarazo adolescente de naturalización de la violencia contra las mujeres y de limitación a los matrimonios igualitarios. La importancia de atender estas omisiones se comprende cuando las estadísticas claramente refieren que en México el $16.2 \%$ de los nacimientos ocurridos durante 2018 corresponden a embarazos de mujeres entre los 15 y 19 años. El 60.4\% de estas adolescentes no utilizó un método anticonceptivo durante su primera relación sexual; de este porcentaje, el 36.4\% indicó que no tenían planeado tener la relación, el 17.3\% afirmó que no sabían de su uso o de cómo obtener dichos métodos y el 16\% aseguró que tenía el deseo de embarazarse. El 12.2\% del porcentaje general tenía ya al menos un hijo previo. Cuatro de cada diez madres adolescentes (41.2\%) indicaron haber vivido al menos un incidente de violencia en los últimos doce meses (Inmujeres, 2020).

Según el Consejo Nacional de Población (CONAPO, 2011), entre los estados del país Chiapas se ubica en una situación muy desfavorable en todo lo relacionado con salud reproductiva, habiendo ocupado entre 2000 y 2010, por ejemplo, los últimos lugares en el uso de anticonceptivos en zonas rurales y de alta presencia in dígena. En sus gráficos históricos sobre el porcentaje de natalidad y fecundidad de mujeres menores de 20 años, el INEGI (2018) constata que, en Chiapas, entre 2010 y 2015 , este porcentaje era superior a la media nacional y se encontraba entre los tres más altos en el país.

El tema de la interrupción legal del embarazo como uno de los derechos sexuales y reproductivos ha encabezado la lucha de los colectivos femeninos en el mundo, los cuales en estos últimos años han generado concientizaciones globales con el apoyo de las redes sociales y las tecnologías de la información. Un ejemplo claro de este fenómeno social ocurrió en Argentina con la "Marea Verde". En este país, a pesar de no haber logrado la legalización del aborto, sí reunieron a un significativo grupo de mujeres afines a su solicitud en el mundo.

Con el paso del tiempo, las activistas proaborto han descubierto y canalizado sus acciones a través de páginas de internet como Facebook, Twitter e Instagram, en las que comunican sus acciones, pero también crean contenidos que tienden a orientar el pensamiento de las generaciones jóvenes sin el influjo de la Iglesia o de sectores conservadores.

\section{La interrupción legal del embarazo en México}

En México desde la declaración del Año Internacional de la Mujer y la incorporación de los derechos humanos como punto nodal de reforma del sistema jurídico mexicano han sido constantes los debates acerca de la despenalización del aborto y de la interrupción legal 
del embarazo. Estos temas se han discutido en varios congresos locales, y las respuestas que se han obtenido han sido negativas, al pronunciarse los legisladores por la protección a la vida "del concebido aún no nacido" como la justificación máxima del sistema legal; a esta postura se suman la influencia que la Iglesia ejerce sobre la población, el discurso político conservador y el posicionamiento de los medios masivos de información.

Maier (2010) señala cómo el escenario en el que estas reformas se fueron dando, desde el sigilo y la opacidad a la ciudadanía, pone de manifiesto la contradicción evidente entre las influencias eclesiásticas y el Estado laico que han marcado la realidad jurídica de nuestro país. En este contexto, el papel del cuerpo femenino "se debate entre estos dos discursos centrados en la capacidad reproductora femenina y las fronteras éticas y normativas de su ejercicio" (Maier, 2010:12), lo que ha significado que en México, en los últimos años, el gobierno presenta una posición ambivalente; por un lado suscribe convenciones internacionales en pro de la libertad femenina $y$, por el otro, presenta argumentos para someter "a consulta pública" derechos humanos fundamentales.

Islas (2009) indica que, desde 1974, mediante el artículo cuarto de la Constitución Política de los Estados Unidos Mexicanos, fracción 3a , se permitía a los hombres y mujeres mayores de edad el derecho a decidir de manera libre, responsable e informada, el número y esparcimiento de los hijos, además de la planificación familiar, como una respuesta a las solicitudes realizadas por el feminismo de los años treinta.

Las activistas de la década de los setenta en México buscaban la "maternidad voluntaria" y, aprovechando que 1975 fue denominado el Año Internacional de la Mujer por las Naciones Unidas, se convocó a la Primera Jornada Nacional sobre el Aborto, a partir de la cual se creó el Frente Nacional de Lucha por la Liberación de los Derechos de las Mujeres.

La Asamblea Legislativa del Distrito Federal promovió en agosto de 2000 una reforma al Código de Procedimientos Penales del Distrito Federal, la denominada "Ley Robles", con la que se proponía la despenalización del aborto bajo tres causas: 1) el riesgo grave de salud hacia la mujer, 2) la existencia de malformaciones en el producto y 3) inseminación artificial no consentida (Lamas, 2009). Si bien el texto fue aprobado por la entonces Asamblea del Distrito Federal, el Partido Acción Nacional y el Verde Ecologista Mexicano presentaron una acción de inconstitucionalidad ante la Suprema Corte de Justicia de la Nación, que se pronunció en favor de la inconstitucionalidad ${ }^{2}$ de la prohibición hacia la despenalización del aborto, e inicio reformas en la Secretaría de Salud del Distrito Federal para regular los procedimientos.

La supresión del delito de aborto en el Código Penal para el Distrito Federal ocurrió en 2004, al incluirse la frase: "se excluye la responsabilidad penal de la mujer", por en ese momento existir ya la causal de "imprudencia de la mujer". En 2007, la Asamblea Legislativa del Distrito Federal inició la argumentación de la interrupción legal del embarazo, mencionando su aprobación si se solicitaba durante las primeras doce semanas después de la fecundación, ${ }^{3}$ buscando la legalidad de métodos anticonceptivos poscoitales y estableciendo la figura del aborto forzado. Nuevamente los grupos conservadores encabezados por la Iglesia católica y el Partido Acción Nacional solicitaron acciones de inconstitucionalidad, con los números 146/2007 y 147/2007; sin embargo, la Suprema Corte resolvió: "El Derecho a la vida del producto no puede ser disminuida frente a la libertad de otra persona, porque la autodeterminación de la mujer se encuentra antes de ejercer el Derecho a la procreación" (CNDH, 2007).

En 2011, en la Constitución se estableció una reforma que obliga desde ese momento al Estado a promover, proteger, garantizar y vigilar el cumplimiento, la protección y defensa de los derechos humanos de sus ciudadanos, comprendiéndolos como derechos fundamentales; asimismo, en los tratados internacionales firmados por México expresamente se atiende el derecho a la libre determinación y desarrollo de las personas, al gozo de los derechos sexuales y reproductivos y a las recomendaciones emitidas para tales efectos por la Organización Mundial de la Salud. ${ }^{4}$

El aborto como tema legislativo en Chiapas data de 1990. A decir de Lamas (2009), en ese año el Congreso de este estado amplió sus razones de no punibilidad, ar- 
gumentando por primera vez: 1) la solicitud de la pareja como medio de planificación familiar, 2) la petición hecha por una madre soltera o 3) por razones económicas. En ese momento, el entonces gobernador de Chiapas, Patrocinio González Garrido —quien posteriormente fue secretario de Gobernación federal — incluso aceptó en una entrevista la realización de abortos clandestinos como problema.

La inclusión de estas causas de no punibilidad al aborto como propuesta en 1990 generó una extensa ola de protestas a nivel nacional. La Iglesia católica, encabezada por Samuel Ruiz en el estado de Chiapas, y el Partido Acción Nacional en todo el país, calificaron de abuso de autoridad la decisión del Congreso local y solicitaron la intervención presidencial para echar marcha atrás a dicha propuesta, logrando incluso su suspensión.

Wójtowicz-Wcisło (2020) sitúa en el año 2009 el reposicionamiento del aborto en la agenda legislativa en México. Como consecuencia de la reforma legal que protege la vida desde el momento de la fecundación en los códigos civiles, que se llevó a cabo en varios estados del país, la fracción parlamentaria del PAN en el congreso local chiapaneco propuso esta modificación en el estado, pero también el establecimiento de la ley de "paternidad responsable", por la que se obliga al padre a sufragar el 50\% de los gastos de embarazo, nacimiento y manutención de los hijos, "partiendo del reconocimiento de la obligación intrínseca en la paternidad y en observancia del equilibrio e igualdad de derechos y obligaciones que debe prevalecer entre el hombre y la mujer" (Wójtowicz-Wcisło, 2020:47). En 2014, el Congreso del Estado de Chiapas conmutó la pena del delito de aborto hacia la "atención integral con perspectiva de género", lo que significa que al día de hoy las mujeres no pagan con pena privativa de libertad, pero sigue considerándose a las mujeres como "sujetos activos" [sic] en la comisión de un delito.

\section{Metodología}

La presente investigación es resultado de tres entrevistas en profundidad realizadas durante el mes de julio de 2019 a las representantes de tres organizaciones de la sociedad civil del estado de Chiapas, quienes fueron ubicadas y seleccionadas a través de Facebook, tomando en cuenta la forma como difunden sus acciones, así como la referencia de otras organizaciones que las señalaron también como las personas idóneas en cuanto a conocimiento del tema. La selección se realizó con base en su actividad principal, su alcance y su militancia en el activismo femenino reconocido en el estado. En cada caso las activistas fueron informadas del objeto, contenido y alcances de la investigación, y cada una otorgó el consentimiento para que sus respuestas se consideraran en una posterior publicación. Para esta investigación se utilizó la entrevista en profundidad, siguiendo cuatro dimensiones, y preguntas clave para detonar la conversación.

Para ello se utilizó una metodología basada en el enfoque cualitativo de Álvarez-Gayou (2003), en la que se abordaron las dimensiones: 1) motivaciones, 2) derechos por los que luchan, 3) capital social y ciudadanía, y 4) redes sociales, a efecto de detonar preguntas que nos llevaran a profundizar en el tema.

\section{El Observatorio Feminista contra la Violencia a las Mujeres de Chiapas (Facebook@ObsFeministaCh)}

Se llevó a cabo una conversación con Dulce V., integrante del Observatorio Feminista contra la Violencia a las Mujeres de Chiapas y de la Red por los Derechos Sexuales y Reproductivos en México (DDESER) desde 2016. Ella manifestó que sus motivaciones para el activismo se relacionan con la toma de conciencia ante las dificultades físicas, morales, materiales y económicas que enfrentan las mujeres jóvenes, sobre todo al verse ante un embarazo no planeado.

Señaló lo doloroso que es para cada mujer ver truncados sus sueños y expectativas futuras y, a la par, cargar con el estigma social y "el castigo que te imponen porque tú te lo buscaste". Su activismo se desarrolla en talleres ofrecidos a estudiantes desde la primaria hasta la universidad, principalmente de secundaria y preparatoria, pero también a padres y madres de familia, quienes 
ella considera que "tienen que estar más informados". En estos talleres, al mencionarse la palabra "aborto, se genera una negativa, entonces entramos con el tema de embarazo adolescente que preocupa, así sí abren las puertas, y con el tema de derechos sexuales, de esa manera vamos sacando poco a poco el tema del aborto, pero sí hay entre los jóvenes esta idea de no hacerlo, de verlo mal y de estigmatizarlo" (entrevista a Dulce V., 2019).

El Observatorio en sí no tiene como uno de sus objetivos la promoción de la interrupción legal del embarazo; sin embargo, la postura de la organización y los contenidos que transmiten están a favor de la legalización. Esta organización informal difunde a través de su página en Facebook contenidos relacionados con los feminicidios ocurridos en Chiapas, con el ánimo de evidenciar su existencia y la omisión de atención por parte de las autoridades. Se pronuncian con relación al aborto "cuando en fechas conmemorativas las organizaciones hacemos una alianza y ahí leemos pronunciamientos, existe un pacto de sororidad ${ }^{5}$ en Tuxtla y en esas ocasiones las organizaciones nos unimos" (entrevista a Dulce V., 2019).

Dulce aseguró que Tuxtla Gutiérrez es una ciudad donde existe activismo femenino, y que el gobierno, en concreto la Secretaría de Salud, les envía condones y anticonceptivos para que los entreguen y distribuyan, aunque los artículos que les donan a veces tienen un período de vida activa muy limitado por la cercanía de la fecha de caducidad; también mencionó que la Secretaría para la Igualdad para las Mujeres de Tuxtla durante el trienio 2018-2021 ha convocado a los grupos feministas para concretar temas vinculados a la equidad de género o la violencia contra las mujeres.

Con relación a las causas que considera generadoras de violencia contra las mujeres, Dulce afirmó que, a pesar de que la alerta de género se encuentra activada en Tuxtla Gutiérrez, la violencia:

es algo que está muy arraigado culturalmente, por más que salgan leyes o propuestas e iniciativas todavía hay mucho machismo; una violencia muy amplia que merma las posibilidades que tanto se están promoviendo, porque, así como hay muchos colectivos y mucho activismo y las nuevas generaciones están con otra visión, pues también se repite mucho en el diario la violencia, hay una creciente violencia que contrarresta el actuar social (entrevista a Dulce V., 2019).

Ante el uso de Facebook como principal medio de difusión, Dulce argumenta el cuidado que tienen en transmitir información de la manera más profesional posible, no solo con el ánimo de evitar la censura, sino también considerando el respeto y la dignidad de las mujeres víctimas del feminicidio y de cualquier otro tipo de violencia.

Entre las mejoras que, según ella observa, deben realizarse para optimizar el trabajo del Observatorio, considera necesario el crecimiento como organización y su formalización, ya que ello les permitiría realizar acciones más concretas como acompañamiento y apoyo psicológico, algo que ahora por lo reducido de su tamaño no pueden realizar.

\section{Mujeres por el Derecho a Decidir (@ddeser.chiapas)}

Zedxi V. es la representante de DDESER en Chiapas; explicó que pertenece a una organización con presencia nacional: Equidad de Género, Ciudadanía, Trabajo y Familia, A.C., que lleva 17 años difundiendo en México los derechos sexuales y reproductivos, y que lleva a cabo acciones orientadas al derecho a decidir de las mujeres. Trabajan con una base social organizada a partir de redes con diferentes lideresas en el país, quienes, tras una capacitación tanto en los derechos como en la forma de implementar acciones sociales a través de la promoción y el voluntariado, impulsan en sus estados acciones sobre todo de carácter político.

Zedxi V. considera que en Chiapas no ha habido posibilidad de hacer cambios legislativos, y las acciones que han emprendido desde su organización se han limitado a vigilar el cumplimiento de, por ejemplo, la Norma Oficial Mexicana 046, “' “acompañando a mujeres que necesitan acceder a un aborto permitido dentro de las causales que establece el código penal en el estado, buscando un acceso a esta posibilidad de manera más 
sencilla" (entrevista, Zedxi V., 2019). Cuentan con una red de abogadas que apoyan en el caso de que surjan conflictos y que orientan sobre la forma de llevar a cabo la interrupción de un embarazo; en su organización, aunque no ofrecen los medicamentos, sí difunden cuáles y cómo deben tomarse si las mujeres asumen la decisión de usarlos, fundamentándose en el derecho al acceso a la información.

También realizan acciones orientadas a crear una opinión favorable respecto al acceso a los derechos sexuales y reproductivos y a su ejercicio pleno, a través de talleres, brigadas, mesas informativas, stands en ferias y una serie de actividades lúdicas, que son posibles en la medida que el presupuesto se lo permita. Obtienen recursos a través de donaciones, sobre todo anónimas, o de proyectos financiados por las fundaciones MacArthur, Ford y Kellogg, y por la Comisión Europea. Sin embargo, ante el recorte de fondos que han sufrido, decidieron a partir de 2017 concursar en proyectos nacionales, en programas como PROEQUIDAD de Inmujeres, aunque con el cambio de las políticas gubernamentales actuales estos programas se han vuelto inaccesibles debido a que dejaron de considerar a las organizaciones de la sociedad civil como sujetos de financiamiento.

Ante este escenario, en DDESER decidieron buscar recursos a fin de promover la participación política para fortalecer a las mujeres que ya tenían posiciones de liderazgo en sus comunidades, en la búsqueda de que puedan ocupar cargos de elección popular o cargos en instituciones de toma de decisiones, ya que consideran que ejercer estos derechos políticos es el camino para la práctica plena de los derechos sexuales y reproductivos de las mujeres.

Zedxi V. inició en el activismo tras asistir a un taller de capacitación sobre autoestima invitada por una prima, varios años atrás; en ese taller reconoció que estaba inmersa en una relación violenta, pero, a pesar de ser consciente de ello, no contaba con las herramientas para poner límites o para abandonarla. Comenzó su activismo en su círculo de amigas cercano, trabajando sobre la prevención de la violencia en el noviazgo, sin tener contacto con derechos sexuales y reproductivos, al grado que: nunca me había cuestionado cuál era mi posicionamiento con respecto al aborto, había escuchado de quienes lo habían hecho, pero nunca había tenido tiempo de pararme a reflexionar qué pensaba yo del aborto o si me pasaba en algún momento qué podría yo hacer, lo que me hizo decidirme a capacitar en el tema de violencia a señoras de varias comunidades; así me empecé a cuestionar cómo era posible que yo diera esos talleres sin resolver mis propios problemas (entrevista, Zedxi V., 2019).

Descubrirse feminista le resultó complicado porque se sentía insegura debido a que no contaba con conocimientos teóricos sobre el tema; sin embargo, indicó: "cuando comprendí que el feminismo implica solo ser consciente y movilizar mis herramientas, las que estuvieran a mi alcance para minimizar y para hacer evidente la opresión contra las mujeres, eso bastaba" (entrevista, Zedxi V., 2019).

Sus reflexiones con relación a la posibilidad de lograr la interrupción legal del embarazo en Chiapas no son positivas. Desde el año 2011 ha estado involucrada en las acciones que cada gobierno ha promovido para cumplir con ese objetivo, y una y otra vez, en cada legislatura, no se han obtenido resultados. Narró cómo en 2015, tras ganar la organización DDESER el Premio Estatal de la Juventud en Chiapas, no pasó nada, pero cuando un año después obtuvo el premio nacional, el Congreso del estado fijó su atención en ellas; en esa oportunidad, aunque hubo muchas fotos y promoción en los medios locales de comunicación, al final su solicitud de impulsar la interrupción legal del embarazo en Chiapas no trascendió.

En la legislatura actual (2019-2024), y considerando que la mayoría de los diputados son del partido Morena, se consiguió que el Grupo de Información en Reproducción Elegida (GIRE) hiciera un mapeo sobre la situación política en Chiapas y capacitara a las mujeres de DDESER para que pudieran realizar cabildeo ante el Congreso, lo que dio origen a la Campaña Estatal para el Aborto Seguro, Legal y Gratuito en Chiapas, donde se agruparon varias organizaciones feministas como DDESER, Fondo María, Católicas por el Derecho 
a Decidir, Mi Útero Feliz, Insurrectas-Políticamente Incorrectas y Mujeres de Maíz, que unidas construyeron una estrategia política y otra de incidencia social, asumiendo una postura de diálogo, más institucional. Contactaron con diez legisladores que les ayudaron a subir el tema de la discusión:

solo dos nos dijeron: "A ustedes sí las llevaría [mujeres], déjenme hablar con mi bancada”, y el resto nos dijeron: "Pues yo estoy abierta al tema pero yo no voy sola, por el costo político"... Creo que lo que no han entendido es que ante la coyuntura actual el costo político es positivo y ellos siguen creyendo que el costo político va a ser desfavorable (entrevista, Zedxi V., 2019).

Es interesante lo puntual e insistente que fue Zedxi con relación a la necesidad de orientar la movilización social y las acciones que hasta el momento pueden considerarse subversivas (difundir los derechos reproductivos con carteles en la ciudad, informar sobre el medicamento por usar para la interrupción legal del embarazo, contar con una red de mujeres dispuestas a financiar la adquisición del medicamento para apoyar a las que no pueden hacerlo, o incluso acompañar desde el anonimato a quienes estén temerosas para someterse al procedimiento) con el objetivo de que se formalicen los derechos sexuales y reproductivos en el Congreso del estado.

Zedxi criticó el sistema del tratamiento integral ${ }^{7}$ como medida correctiva hacia las mujeres que se han realizado un aborto clandestino en Chiapas confrontando: el anuncio de la "despenalización" hecho por el gobernador de Chiapas en 2009 y, a la vez, el anuncio de la publicación de la Ley de Paternidad Responsable y la protección del embrión desde el momento de la fecundación.

Es notorio que, acorde a la organización a la que representa, para esta activista los esfuerzos realizados desde su activismo no son suficientes; narró cómo han intentado también desde el centro del país impulsar una reforma legal en Chiapas, considerando el momento político en el que México se encuentra con la llegada de Morena al poder federal y la integración a la Secretaría de Gobernación de juristas como Olga Sánchez Cordero; sin embargo, ve que el presidente de la República, e incluso Nadine Gasman del Instituto Nacional de las Mujeres, no asumen una postura "firme y no neutral ante temas firmes e importantes para las mujeres [...] Pero en Chiapas no va a pasar, hay avances en Puebla, Hidalgo, Michoacán e incluso Oaxaca, ${ }^{8}$ en donde ya hay iniciativas presentadas" (entrevista, Zedxi V., 2019).

$\mathrm{Al}$ preguntarle por qué la interrupción legal del embarazo no es un tema abordado por los Congresos locales, en donde debe ser presentado por disposición legal en México, señaló con especial énfasis Hidalgo, estado en el que resultó problemático definir quién lo presentaba por el gran de capital político que implicaba, es decir, los legisladores se peleaban por ser considerados como "los progresistas" en su estado. Sin embargo, Zedxi no veía esta objeción en Chiapas; mencionó que en DDESER han hecho ejercicios sociales a muy baja escala, como sondeos en escuelas y universidades, y que, si la gente no está a favor, al menos es neutral, "y lo neutral es para nosotras a favor".

El problema social es nacional, ahí ganó fuerza el movimiento Pro-Vida, una de cuyas estrategias fue la misma que la nuestra: crear base social en diferentes lugares del estado. En Chiapas, el año pasado cobró fuerza y ya tiene una representante, algo que no había pasado nunca; ya tiene una red, han celebrado marchas, ya tienen acercamiento con las legisladoras... otro revés que nos dieron fue que colocaron como presidenta de la Comisión de Equidad de Género a una mujer sumamente conservadora, que en su discurso de toma de posesión dijo que va a luchar por la defensa de la vida y de la familia, y sabemos lo que eso significa: no aborto, no ILE (entrevista, Zedxi V., 2019).

\section{Mi Útero Feliz (Facebook @MiÚteroFeliz)}

Pato S. es enlace de Fondo María en Chiapas desde 2016 y forma parte de la campaña estatal por el aborto legal, seguro y gratuito en Chiapas que nació en 2018; 
su principal proyecto, del que es fundadora, se llama Mi Útero Feliz. Se trata de una plataforma digital presente en todas las redes sociales - Facebook, Twitter, Instagram, Gmail-, que tiene como objetivo brindar información segura, confiable y de forma amigable y entendible a las mujeres de todas las edades sobre salud sexual y reproductiva, derecho a decidir, menstruación consciente, y en general los derechos sexuales y reproductivos.

Inició en el activismo tras sentir que "todo estaba mal", y en ese inter descubrió una convocatoria de trabajo de Fondo María para ser el enlace de esta organización en Chiapas. A partir de entonces pudo comprender que la convicción de malestar que sentía era resultado de una sociedad heteropatriarcal que domina sobre las mujeres y era compartida por más mujeres. Así, tras comenzar a trabajar como enlace de Fondo María, inició la realización de una serie de talleres y campañas hacia mujeres, jóvenes y niños, para lo cual diseñó un peluche al que llama Mi Útero Feliz (ver Imagen 1).

Es elútero feliz y obviamente es como muy kawaii, muy lindo, y con este trataba, bueno, explicaba todo el proceso de la menstruación. Una amiga me dijo: 'Deberías hacerle una página'. Yo ya traía ganas de un proyecto propio, hice la página y dije: se va a enfocar hacia la salud sexual y reproductiva de las mujeres, derechos sexuales y reproductivos, y al principio era solo yo; hasta hace un mes que ya está como conformado el grupo de Mi Útero Feliz por activistas que ya tienen experiencia en el tema y que están súper comprometidas con el proyecto y sobre todo con cambiar esta situación (entrevista, Pato S., 2019).

A pesar de que en un principio Pato S. pensaba que las redes sociales no generaban compromisos en el activismo, ya que "solo posteas memes y discutes sin argumentos, me di cuenta de que a veces no puedes estar de manera presencial con las mujeres, y con tener un acompañamiento o una asesoría digital le puedes cambiar la vida. Entonces dije: 'Haré activismo digital', lo digital es lo que ha jalado más por la inmediatez de las redes" (entrevista, Pato S., 2019).
Fundado el 24 de abril de 2017, y gracias a una publicación sobre violencia obstétrica replicada, este medio incrementó su número de seguidores de los 1700 originales, a los 34000 con los que cuenta actualmente - provenientes de Chiapas, del resto de México, de otros países de América Latina y el Caribe, y de comunidades latinas y chicanas en Estados Unidos-. A decir de esta activista:

Tuvimos el crecimiento que no habíamos tenido en dos años, bueno, no me la creía. Estamos muy contentas porque aparte hemos podido acompañar a distancia a varias chicas que han decidido interrumpir su embarazo de manera segura en casa; brindamos información, no solo en cuestiones de derecho a decidir sino también en temas con un poco de violencia o de chicas, mujeres que han perdido su útero por enfermedades y que no saben con quién hablarlo y que no saben si son más o menos mujeres por ello. Todas estas cuestiones que a veces no tienes confianza de platicar con alguien, en Mi Útero Feliz tienen la confianza de hacer este trabajo como de catarsis; si nos escriben, siempre les vamos a responder, sea la hora que sea, y pues también hemos hecho campañas de entrega de métodos anticonceptivos, etcétera (entrevista, Pato S., 2019).

Su búsqueda se centra en el derecho a la decisión de las mujeres, ya que:

[...] lo que nosotras queremos es que las mujeres que quieran ser madres tengan las condiciones idóneas para serlo, que en Chiapas y en México no hay. Nuestro valor primordial como sociedad mexicana es la maternidad, y sin embargo no procuramos que las madres y las criaturas tengan una calidad de vida digna antes, durante y después del parto. Y también lo que queremos es que las mujeres que en su momento no quieran ejercer la maternidad también puedan libremente decidirlo (entrevista, Pato S., 2019).

Al preguntarle sobre su posicionamiento ante la visión en Chiapas del aborto como un delito, es clara 
al afirmar que se necesita considerar el derecho a la libre elección de las mujeres como fundamento para permitir la interrupción legal del embarazo; sabe que desde el gobierno de Patrocinio González Garrido no ha existido una propuesta que permita el ejercicio pleno de los derechos sexuales y reproductivos de las mujeres y, por eso, ella participó en la emisión del Parlamento Juvenil en Chiapas de 2019 .

Durante el mes de octubre de 2019 se llevó a cabo la novena edición del Parlamento Juvenil Rosario Castellanos, espacio creado por el Congreso de Chiapas para promover que jóvenes de 15 a 29 años de edad presenten una iniciativa ante el pleno y la defiendan. Fueron seleccionadas 40, de acuerdo con el número de diputados existentes en el estado. La idea de este ejercicio es que las iniciativas seleccionadas sean adoptadas por alguno de los diputados o diputadas del Congreso y puedan llevarse a la sesión y promulgarse. En esta sesión Pato logró promover su iniciativa y quedó entre las seleccionadas; en ese momento solicitó el aumento de las excluyentes al delito de aborto por razones socioeconómicas y por riesgo a la salud de la mujer.

Al momento de la entrevista Pato se encontraba realizando no solo el contenido de su participación, sino también una estrategia de red de apoyo, ya que tenía muy clara la necesidad de generar redes entre activistas que se unieran para presentar todas una misma propuesta:

$[. .$.$] creo que es muy importante que se presente$ una iniciativa de este tipo, y que todas nos unamos y vayamos a hacer presión al Congreso, ino?, o sea, que estemos detrás de la diputada o diputado que abrace cualquier iniciativa de interrupción legal del embarazo para hacer la presión: icuándo la presentas? , ¿quiénes la van a votar? Estar al pendiente de las sesiones, porque tú sabes que a veces se hacen sesiones exprés y no te avisan; te enteras que no pasó porque ya se hizo la sesión y no fuiste a hacer presión, o sea, hay que tener tiempo y estrategia política (entrevista, Pato S., 2019).
La activista reconoció que "la falla" que han tenido las organizaciones civiles en Chiapas tiene que ver con la falta de unión para el logro de los objetivos comunes:

[...] lo único que falta es que de verdad nos unamos para poder hacer presión por alguna ley o algún cambio. Es difícil porque cada quien tiene su vida, sus intereses, su feminismo, incluso; isabes?, hay muchas vertientes, respetamos el trabajo de la una y de la otra, pero a veces es difícil coincidir o estar de acuerdo en ciertos puntos de vista. Creo que en algún momento vamos a entender eso, debemos estar unidas porque eso es lo importante, que yo no podré estar de acuerdo con ella, pero si ella te va a ayudar a ti en tu línea, adelante. Aunque no estemos de acuerdo no nos ponemos el pie, porque hay feministas más radicales y yo podré no estar a lo mejor de acuerdo, pero te respeto y no te pongo el pie (entrevista, Pato S., 2019).

Pato cree firmemente en la movilización ciudadana para la transformación de los derechos reconocidos en México. Considera que, si la interrupción legal del embarazo no se logra a través del Congreso, entonces podrá ocurrir lo mismo que con el matrimonio igualitario, que, aunque en Chiapas no se legalizó, la ciudadanía fue a la Suprema Corte de Justicia y se logró una jurisprudencia para casarse; sin embargo, entendía que los derechos no deben llevarse al litigio: "si de todas maneras el sistema va a ceder, debería hacerlo desde el momento de permitir los mismos derechos" (entrevista, Pato S., 2019).

Pato ha encontrado en las redes sociales un medio de difusión efectivo; al cuestionarle sobre la titularidad de los derechos de autor tanto de su página como de la imagen, ella la piensa como marca. Con relación a la forma como se comunica con quienes acuden a la página de Mi Útero Feliz, mencionó que utiliza un lenguaje asequible, "para que no sientan que están hablando con un doctor o una señora”, y sus contenidos varían desde "dar mensajes de empoderamiento, hacemos infografías sobre violencia, nos 
enfocamos en otros temas de feminismo, pero sí con más visibilidad hacia la salud sexual y reproductiva" (entrevista, Pato S., 2019).

Los hombres también participan en su página; mencionó que le han consultado dudas o le han dejado comentarios:

[...] pero si vienes a decirnos vulgaridades, a decirlo de manera sarcástica, prepárate porque te vamos a eliminar, te vamos a reportar y te vamos a bloquear. Tomamos nuestras medidas, te digo que con lo de violencia obstétrica tuvimos que sacar hasta un comunicado de "esto es para mujeres, todo comentario fuera de lugar será eliminado y bloquearemos a quien lo realice". No damos información de interrupción del embarazo a hombres, de otros temas de sexualidad sí porque hay dudas que desde chicos tienen; en México tú sabes que la educación sexual integral no existe, entonces llegan con estas dudas muy válidas, adelante, pero sobre interrupción no damos, y no enfocamos a las mujeres (entrevista, Pato S., 2019).

Para Pato, el activismo cada vez está más en boga, y en el estado de Chiapas, que desde el siglo pasado ha sido pionero en cuestión de lucha por los derechos sexuales y reproductivos, nunca se ha dejado de luchar. Considera el activismo como un trabajo de toda la vida, pero con relevos generacionales ya que los jóvenes tienen más empuje.

\section{A manera de conclusión}

México tiene como tema pendiente garantizar plenamente el derecho humano de la libre decisión para las mujeres y la plena observancia de los derechos sexuales y reproductivos: existen esfuerzos desde varios estados de la República que evidencian la incongruencia del sentir reformista acorde a la igualdad, la universalidad y la libertad que enarbolan los derechos humanos y su pleno ejercicio.

El reconocimiento obtenido por las mujeres hacia la salvaguarda y satisfacción de estos derechos se ha logrado comúnmente desde la movilización social, aprovechando los momentos históricos y políticos. Es así como en la Ciudad de México, y actualmente en el estado de Oaxaca, se ha logrado la interrupción legal del embarazo, lo que resulta incomprensible ante la firma de convenciones internacionales, que cuentan con el mismo valor jerárquico de la Constitución política y obligan al Estado mexicano —es decir, a la Federación - a su cumplimiento, lo que ha sido abordado exclusivamente con la emisión de Normas Oficiales como la 046, en acciones eminentemente administrativas. En este sentido, el estado de Chiapas cuenta, por ejemplo, con un procedimiento previsto en el Manual del Centro de Justicia para las Mujeres, utilizado en caso de la comisión de un delito sexual.

Comprender la interrupción legal del embarazo con una visión acorde a los derechos humanos significa, por parte del Estado mexicano, asumir plenamente las obligaciones adquiridas frente a las libertades fundamentales que se reconocen y exigen desde el derecho internacional, ejerciéndolas en el ámbito local; estas obligaciones comprenden el actuar de todas las legislaciones, instituciones, servidores públicos y presupuestos hacia la promoción, protección y vigilancia plena al goce y disfrute de, en el caso que nos ocupa, la libertad de autodeterminación de las mujeres y el ejercicio de los derechos sexuales y reproductivos; es decir, el permitir a las mujeres experimentar una vida conforme decida vivirla sin tener que verse sometida a una maternidad no deseada, lo que en sociedades como la mexicana se limita de facto con la negación de estos derechos fundamentales.

Esta negación da origen a variadas formas de violencia contra la mujer, considerando para esta conclusión exclusivamente la institucional que presenta serias deficiencias en la atención y promoción de los derechos sexuales y reproductivos de las mujeres, permitiendo la repetición de acciones que las desvalorizan y en ocasiones las orillan a escenarios tan adversos como la maternidad adolescente.

Las activistas chiapanecas están conscientes de la necesidad, responsabilidad, trabajo y estrategias 
que se requieren para lograr que en el estado la interrupción legal del embarazo sea posible; sin embargo, no solo comprenden ese como el problema central por atender, su compromiso con la difusión de los derechos de salud sexual y reproductiva comienza desde la capacitación que dichas activistas realizan a menores de edad, a sus padres y a profesores, y a través de la difusión de medidas e incluso de la entrega de anticonceptivos que permitan el ejercicio de una vida sexual plena y sin problemas.

Su pertenencia a redes nacionales e internacionales de lucha y defensa de los derechos sexuales y reproductivos se constata en su formación y desenvolvimiento, tanto en el discurso como en las acciones que realizan, y en el empleo de redes sociales para alcanzar a la mayor población vulnerable posible. Lo anterior las ha llevado a generar alternativas que las distinguen e identifican, tanto por sus objetivos como por sus particulares formas de acción. El Observatorio feminista y Mi Útero Feliz son referentes en Facebook, donde cuentan con seguidores que van incrementando y replicando sus contenidos, expandiendo su difusión. Las entrevistadas coinciden en la necesidad de elevar a ley la interrupción legal del embarazo, y aunque en apariencia existen diferentes convicciones en cuanto al cómo, cada una coincide en que podrá alcanzarse a través de un representante popular que esté dispuesto a llevar a la escena política la propuesta y que la defienda como el derecho humano que es, aunado a la postura de la legislación federal y al contenido de las recomendaciones internacionales hechas a México. Será entonces cuando el proyecto de legalización sobre el tema pueda consolidarse.

Finalmente, es claro que el activismo femenino en Chiapas existe y avanza en la solicitud de igualdad y pleno ejercicio a la libertad de los derechos de la mujer, que el apoyo obtenido a través de las redes sociales es transgeneracional, y que se percibe una ciudadanía cada vez más empoderada y resuelta a lograr la inclusión y el desarrollo de sus derechos en la agenda política estatal.

\section{Notas}

${ }^{1}$ La Plataforma Beijing surgió tras los esfuerzos de las Convenciones Internacionales de las Mujeres como un espacio creado para facilitar, con el uso de las tecnologías y su difusión, acciones tendientes al empoderamiento y la disminución de la desigualdad, así como la promoción de los derechos humanos de las mujeres (ONU Mujeres, 2014).

${ }^{2}$ La acción de inconstitucionalidad es un recurso basado en el derecho constitucional mexicano que permite la intervención de la Suprema Corte de Justicia de la Nación para resolver las controversias suscitadas por la jerarquía de dos derechos defendidos, en ordenamientos jurídicos de la misma jerarquía, al abordar un mismo supuesto jurídico. El pronunciamiento hecho por la Suprema Corte de Justicia hace que la ley superada pierda su vigencia o se vuelva inaplicable.

${ }^{3}$ Resulta muy interesante comprender la discusión realizada en el pleno de la Asamblea Legislativa en diciembre de 2007, en el que los conceptos "concepción" y "fecundación" fueron enarbolados por los representantes de los diferentes partidos políticos y los sectores a los que se asociaban. Por su parte, el Partido Acción Nacional argumentó durante todo el debate el término "concepción" para reforzar la necesidad de proteger la vida tal y como se establecía en el artículo 144 del Código Penal del Distrito antes de la reforma, concepto del que el diputado Ezequiel Rétiz indicó en su participación tomaba del Colegio de Bioética de Nuevo León y explicando la visión contraria a permitir el aborto. Por otro lado, la palabra "fecundación" fue utilizada a lo largo del dictamen para justificar la autorización del aborto (ALDF, 2007).

${ }^{4}$ Puede establecerse una relación descriptiva, no limitativa, conforme a los derechos que nos ocupan desde la Declaración de los Derechos del Hombre, la Convención sobre la Eliminación de Todas las Formas de Violencia contra la Mujer y la Convención Belém do Pará, entre otras, las cuales a partir de la reforma comentada tienen el mismo nivel jerárquico que la Constitución Política, es decir, que su uso e interpretación está por encima de 
las leyes federales (secundarias) y las estatales, lo que ha venido reformando el contenido de legislaciones y jurisprudencias a modo y actualizando el derecho de manera más inmediata.

${ }_{5}^{5}$ Celia Amorós en su texto "Violencia contra las mujeres y pactos patriarcales" diserta acerca de este pacto hecho entre mujeres que luchan contra la exclusión creada por el "pacto de la hermandad" de los varones, quienes desde su esfera de poder impactan en todas las esferas culturales y jurídicas en las que estamos envueltos (Amorós, 1990).

${ }^{6}$ Esta norma garantiza el acceso a la interrupción legal del embarazo de las mujeres en caso de ser víctimas de violación sexual.

${ }^{7}$ En el anuncio de la Feria Chiapas de 2009, Juan Sabines Guerrero, entonces gobernador del estado, dio a conocer en los medios que desde ese momento en Chiapas el aborto estaba despenalizado, es decir, las mujeres que se realizaran un aborto en el estado ya no pisarían la cárcel, en su lugar habría una sanción consistente en el "tratamiento integral a las mujeres por un tratamiento médico integral en libertad, que será proporcionado por las instituciones de salud a fin de ayudarles a superar los efectos de la intervención y reafirmar los valores humanos de la maternidad" (Mariscal, 2009).

\section{Referencias}

ALDF (Asamblea Legislativa del Distrito Federal) (2007). Diario de debates de la ALDF, 1(12). Disponible en http://aldf.gob.mx/archivo-758210fce6f5232bc6f068dfc58dd9bb.pdf

Álvarez-Gayou Jurgenson, Juan Luis (2003). Cómo hacer una investigación cualitativa. Fundamentos y metodología Buenos Aires: Paidós.

Amorós Puente, Celia (1990). "Violencia contra las mujeres y pactos patriarcales”. En Cristina Sánchez Muñoz, Virginia Maquieira d'Angelo (coords.), Violencia y sociedad patriarcal. Madrid: Editorial Pablo Iglesias, pp. 39-53.
CONAPO (Consejo Nacional de Población) (2011). Perfiles de salud reproductiva. Chiapas. México: CONAPO. Disponible en http:/www.conapo.gob.mx/work/ models/CONAPO/perfiles_salud_reproductiva_estados/Perfiles_SR_07_CS.pdf

CNDH (2007) "Acción de inconstitucionalidad 146/2007" Disponible en https://www.cndh.org.mx/ sites/default/files/doc/Acciones/Acc_Inc_2007_146_ Demanda.pdf

Inmujeres (2020). "Madres adolescentes”. Disponible en http://estadistica.inmujeres.gob.mx/formas/tarjetas/ Madres_adolescentes.pdf

Islas de González Mariscal, Olga (2009). "El aborto en México y Latinoamérica”. En Luz María Valdez (coord.), Derechos de los mexicanos. Introducción al Derecho Demográfico. México: Instituto de Investigaciones Jurídicas-UNAM, pp. 131.163. Disponible en http:// ru.juridicas.unam.mx/xmlui/handle/123456789/11550

Lamas, Marta (2009). "La despenalización del aborto en México”. En NUSO, 220, marzo-abril. Disponible en https:/nuso.org/articulo/la-despenalizacion-delaborto-en-mexico/

Maier, Elizabeth (2010). "El aborto y la disputa cultural contemporánea en México". En La Aljaba, segunda época, XIV, 11-30.

Mariscal, Ángeles (2009). “Aprueban en Chiapas ley regresiva sobre el aborto; impone 'tratamiento sicológico"'. En La Jornada, 19 de diciembre, 24.

ONU (s/f). "Derechos humanos". Disponible en https:// www.un.org/es/sections/issues-depth/human-rights/ index.html (consultado el 18 de febrero de 2020)

ONU Mujeres (2014). Declaración y Plataforma de Acción de Beijing: Declaración política e instrumentos resultados de Beijing+. Nueva York: ONU. Disponible en https://www. unwomen.org/-/media/headquarters/attachments/ sections/csw/bpa_s_final_web.pdf?la=es\&evs=755

Wójtowicz-Wcisło, Marta (2020). "El derecho al aborto electivo en Chiapas, México". En Revista Europea de Estudios Latinoamericanos y del Caribe, 110, junio-diciembre, 39-58. 
Imagen 1. Peluche emblema de Mi Útero Feliz

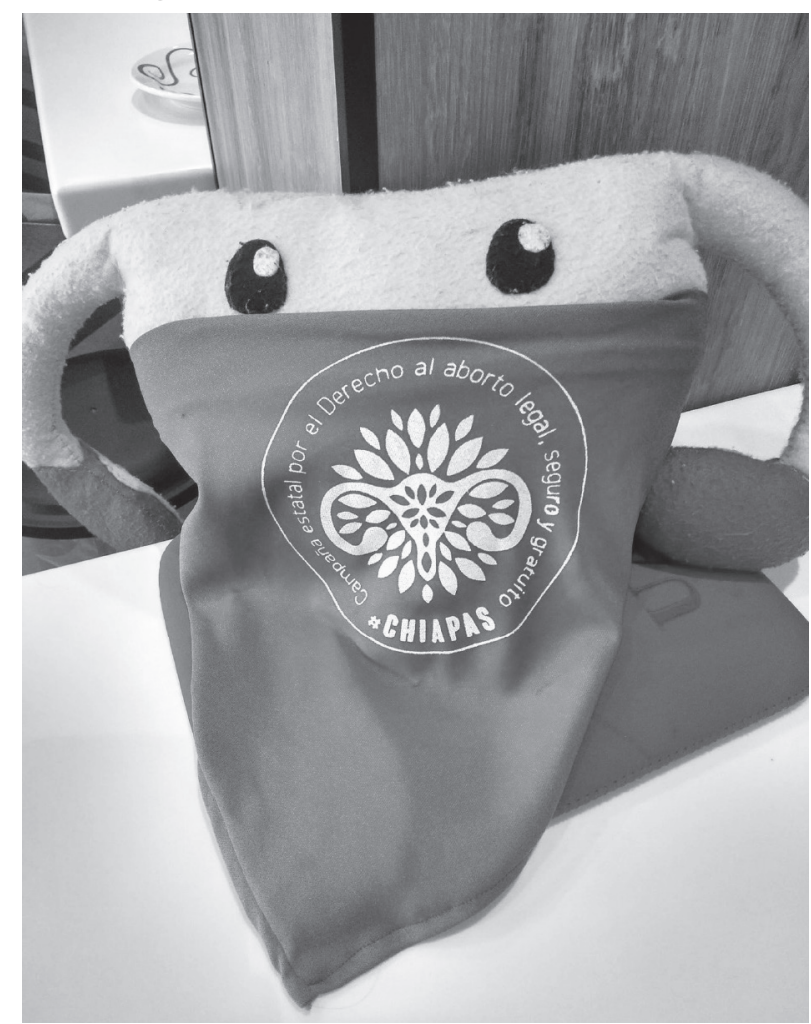

Fuente: Alma Soberano. Tomada de: https://www.facebook.com/AlmaASoberano/photos/a.1763751247275796/2333476293636619 